\title{
Mechanical and Spectroscopic Characterization of Solute Elements in Aluminum
}

\author{
Seiichiro $\mathrm{Ii}^{*}$, and Toru Hara \\ Research Center for Structural Materials, National Institute for Materials Science, Tsukuba, 305-0047 Japan
}

\begin{abstract}
We characterized the distribution of minor elements such as $\mathrm{Si}$ and $\mathrm{Fe}$ in $\mathrm{Al}$ utilizing a nanoindentation and electron microscopy with an energy dispersed X-ray spectroscopy (EDS) system. Nanoindentation can detect the dislocation nucleation known as "pop-in" event, the critical load (Pc) depends on the solute amount of Fe. However, that in Si-doped $\mathrm{Al}$ is rarely changed up to 1.0 at\% of Si. That independent Pc in Al-Si is caused by the inhomogeneity of the Si, which is the grain boundary segregation, in Al. The grain boundary segregation of Si was clearly detected by using a newly developed microcalorimeter type EDS system, even at the 0.1 at $\% \mathrm{Si}$.
\end{abstract}

\section{INTRODUCTION}

The mechanical properties of $\mathrm{Al}$ alloys are mainly achieved by the microstructure control, especially the controlling of precipitates [1]. In order to control the shape, size, and volume fraction of the precipitates, the distribution of the supersaturated alloying elements is one of the important factors. The quantitative analysis for alloying elements has been analyzed by several techniques based on chemical and physical properties of alloying elements in Al. As for chemical analyses, an inductively coupled plasma atomic emission spectrometry (ICP-AES) and an atomic emission spectrometry (AES) are often used for the quantitative measurement of the chemical composition $[2,3]$. On the other hand, from a physical standpoint, the internal friction and electrical resistivity are also used for the analysis of impurities [4, 5]. However, above techniques measure the only average composition of the specimen or the wide region in the alloys. Recently, the importance of the heterogeneity of the materials in the microstructure is also pointed out [6], the quantitative analysis of the alloying elements at local region becomes more crucial.

As for the local analysis in the chemical and physical methods, several techniques combined with the microscopy are often used. The representative technique is energy dispersed X-ray spectroscopy (EDS) combined with electron microscopy. In a decade, Tanaka et al. have developed the new type of analytical scanning electron microscope (SEM) attached with a microcalorimeter-type EDS [7]. By this analytical SEM, the chemical analysis in the special resolution of SEM can be conducted with an energy resolution of around 10 $\mathrm{eV}$, which is one order higher than the conventional EDS system. It means that the elements in materials are identified with accuracy, even for a multicomponent system. In addition to the improvement of the energy resolution, the sharpness of each peak in the spectrum assists the improvement of the detection limit for the minor elements because of high peak/background $(\mathrm{P} / \mathrm{B})$ ratio.

Besides, the alloying elements also act as the obstacle, that is, as solute strengthening [8]. It depends on the misfit strain between alloying elements and $\mathrm{Al}$ matrix and the distribution of the alloying elements. Especially, the misfit strain of $\mathrm{Fe}$, which is known as a typical impurity in $\mathrm{Al}$, is remarkable larger than the other elements and it is expected as a solute strengthening element in recent. To investigate the local mechanical responses, the nanoindentation technique is widely used [9]. In the load (P) - displacement (h) curve obtained by the nanoindentation test, the discontinuous change in strain or stress is frequently seen during the loading. This phenomenon is known as "pop-in" event, and it is recognized as the dislocation nucleation and multiplication [10]. Since the solute strengthening is related to a dislocation interaction with the solute atoms, we, therefore, expect the possibility of nanoindentation technique for the mechanical measurement of the element distribution.

In this study, we here report that the mechanical and chemical effects of minor elements such as $\mathrm{Fe}$ and $\mathrm{Si}$ are characterized by spectroscopic of microcalorimetertype EDS installed to scanning electron microscopy (SEM) and nanoindentation technique and discuss the possibility as the characterization for the minor elements in $\mathrm{Al}$ alloys.

\section{Experimental procedure}

The pure Al, Al-Si and Al-Fe alloys are fabricated by the high-frequency induction melting technique in an argon atmosphere. Chemical composition of ingots is analyzed

Corresponding author: II.Seiichiro@nims.go.jp 
Table 1. Chemical composition in $\mathrm{Al}$ alloys (at \%)

\begin{tabular}{|c|c|c|c|c|}
\hline & $\mathrm{Fe}$ & $\mathrm{Si}$ & $\mathrm{Cu}$ & $\mathrm{Al}$ \\
\hline Pure Al & $<0.001$ & 0.001 & $<0.001$ & bal. \\
\hline $\mathrm{Al}-0.02 \mathrm{Fe}$ & 0.0251 & $<0.001$ & $<0.001$ & bal. \\
\hline $\mathrm{Al}-0.04 \mathrm{Fe}$ & 0.0459 & $<0.001$ & $<0.001$ & bal. \\
\hline $\mathrm{Al}-0.1 \mathrm{Si}$ & $<0.001$ & 0.1 & $<0.001$ & bal. \\
\hline Al-1.0Si & $<0.001$ & 1.0 & $<0.001$ & bal. \\
\hline
\end{tabular}

by an ICP-AES and listed in table 1 . The ingots were homogenized at $873 \mathrm{~K}$ for $10.8 \mathrm{ksec}$ in air and then hot and cold rolled. The plate was cut into a square with 10 $\mathrm{mm}$ one side and arbitral thickness and solutionized in

(a)

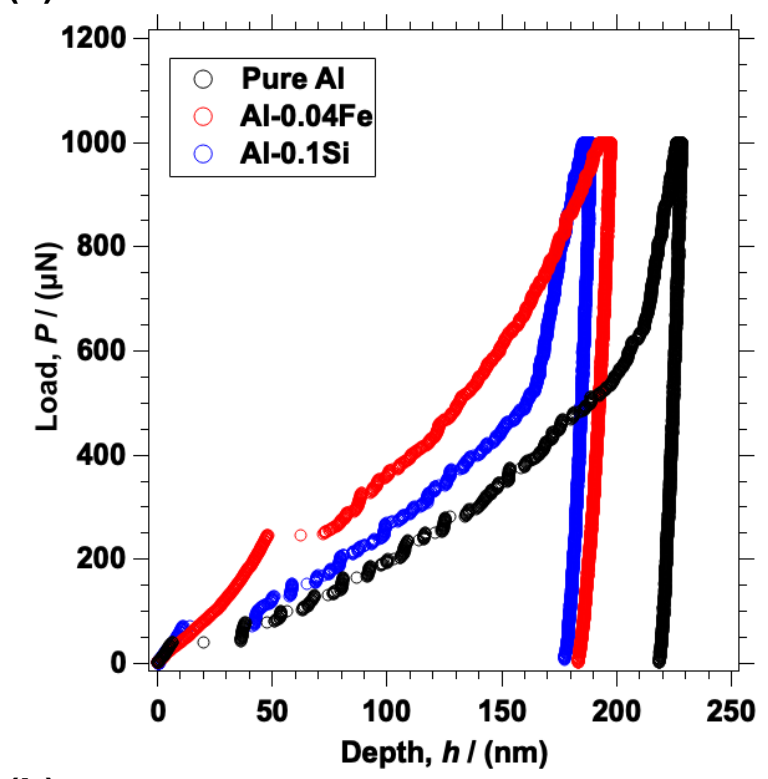

(b)

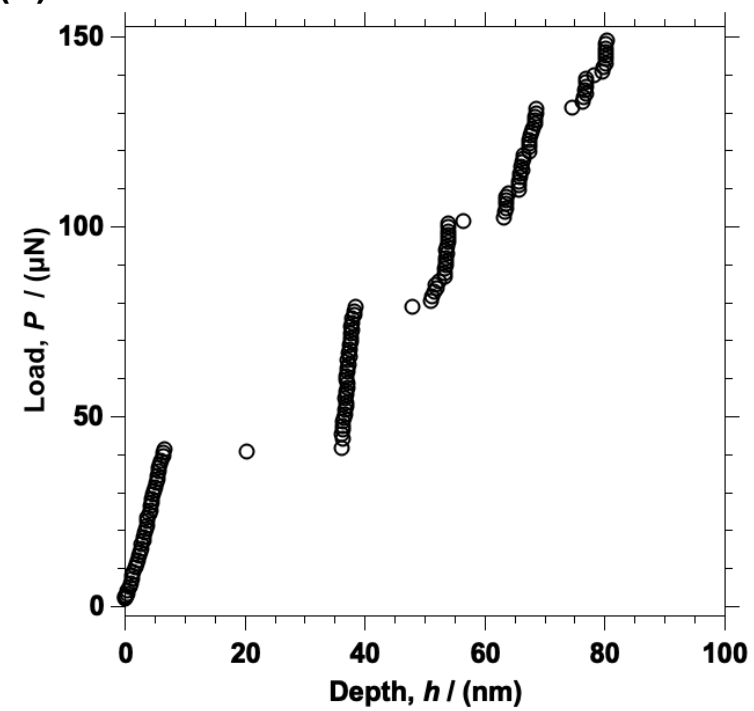

Figure 1 (a) Load - displacement curves obtained from pure Al, $\mathrm{Al}-0.04$ at $\% \mathrm{Fe}$ and $\mathrm{Al}-0.1$ at $\% \mathrm{Si}$ alloy, which are plotted as circle (pure $\mathrm{Al}$ ), square (Al- $0.04 \mathrm{at} \% \mathrm{Fe}$ ) and diamond (Al- 0.1 at $\% \mathrm{Si}$ ), respectively. (b) Enlarged $\mathrm{P}-\mathrm{h}$ curve of pure $\mathrm{Al}$ showing the beginning of the nanoindentation. The discontinuous strain phenomena are indicated by arrows. This discontinuity is known as "pop-in" event, which is recognized as the nucleation and multiplication dislocation. air. The specimens were mechanically and electrochemically polished with a mirror surface. The local mechanical response was evaluated by the nanoindentation (TriboIndentator: TI950 Hysitron Co.) was used. An indentation rate and a maximum load are $0.1 \mu \mathrm{N} / \mathrm{sec}$ and $1 \mathrm{mN}$, respectively. We measured the mechanical responses at several ten points in grain interior for a few grains. The chemical analysis at the grain interior and grain boundary was performed by the microcalorimeter EDS equipped onto SEM (Ultra55, Carl Zeiss AG.) installed in Kyushu university. Observation was performed at an acceleration voltage of $5 \mathrm{kV}$. As a reference, the EDS spectra by conventional silicon drift detector were also obtained simultaneously. The grain boundary analyzed by EDS was the random grain boundary with the misorientation angle of $35.5^{\circ}$ around [25 -3 16] measured by OIM.

\section{Results and discussion}

\subsection{Measurement of local mechanical response by nanoindentation and the effect of solute elements of $\mathrm{Si}$ and $\mathrm{Fe}$ in $\mathrm{Al}$}

Figure 1 (a) shows load $(\mathrm{P})$ - depth (h) curves obtained from pure $\mathrm{Al}, \mathrm{Al}-\mathrm{Fe}$ and $\mathrm{Al}-\mathrm{Si}$ alloys, respectively. All indentation tests are examined in the grain interior, and the effect of grain boundaries on the mechanical response in the alloys is eliminated. In all $\mathrm{P}-\mathrm{h}$ curves, one can see the discontinuous strain jump at the early stage of the deformation as shown in fig.1 (b) which is enlarged P-h curve correspoinding to the beginning of the nanoindentation in pure Al. That discontinuous event is known as "pop-in" and this is considered to be a strain burst due to the nucleation and/or multiplication of the dislocations. Furthermore, the load $\mathrm{P}$ at the first pop-in event is recognized as a critical load $(\mathrm{Pc})$. This is confirmed as the first event of the dislocation nucleation

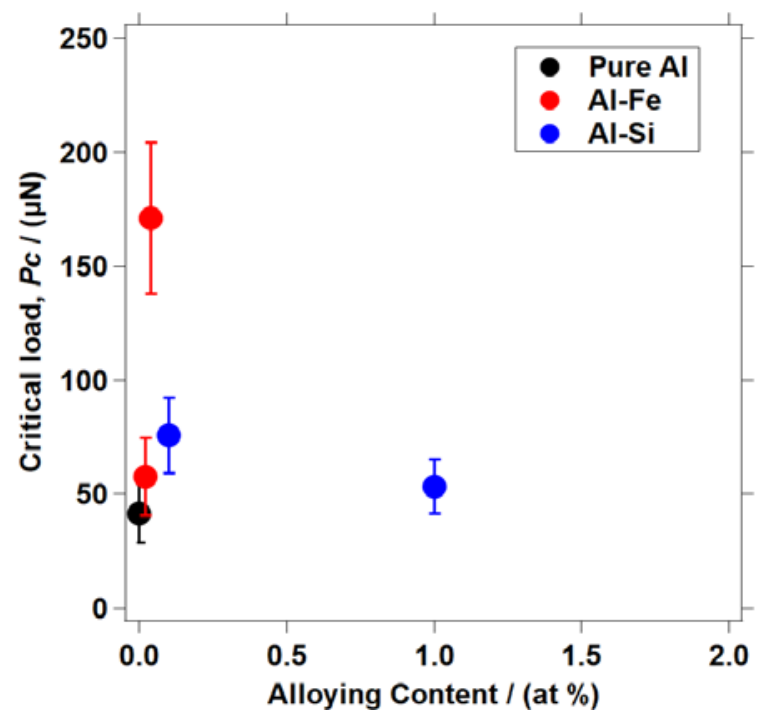

Figure 2 The effect of alloying contents of Fe and Si on the critical load, Pc in load-displacement curve in nanoindentation measurement for Al alloys. Open circle and solid circle are showing the results of $\mathrm{Fe}$ and $\mathrm{Si}$, respectively. 
and growth at the defect-free region [11]. Figure 2 shows the effect of $\mathrm{Fe}$ and $\mathrm{Si}$ addition on the $\mathrm{Pc}$ in $\mathrm{Al}$. Pc in every specimen fluctuates indicated as an error bar in fig.2. Thereby, we expect that the pop-in event is presumed as a thermal activation process. Fe addition in $\mathrm{Al}$ remarkably increases the $\mathrm{Pc}$ of $\mathrm{Al}$ alloy, and the $\mathrm{Pc}$ is almost linearly increased with increasing Fe contents, even if alloying contents of $\mathrm{Fe}$ is small, which is approximately 0.046 at $\%$. On the other hand, Si addition up to 1.0 at $\%$ fewer influences rather than $\mathrm{Fe}$ addition. The relationship between solutions and $\mathrm{Pc}$ has been reported in steel [12] and in $\mathrm{Mg}$ [13]. Those can be recognized as the solute strengthening, in which the solutions act as an obstacle for dislocation motion. Uesugi and Higashi have studied the solute strengthening in $\mathrm{Al}$ from the standpoint of ab-initio calculation $[14,15]$. They reported that the misfit strain of $\mathrm{Fe}(-3.9 \%)$ in $\mathrm{Al}$ matrix provides much higher misfit strain than the other elements, which are often included in $\mathrm{Al}$ such as $\mathrm{Si}, \mathrm{Mg}$, and $\mathrm{Cu}$, in their report. Their report is well-consistent with our results obtained by nanoindentation. Therefore, the reason for the increment of Pc is owing to strengthening by solutions and larger misfit strain of solute $\mathrm{Fe}$ in $\mathrm{Al}$ matrix significantly affects to Pc in comparison with Si. On the other hand, $\mathrm{Pc}$ in $\mathrm{Al}-\mathrm{Si}$ is not change very much, even at $1.0 \mathrm{at} \% \mathrm{Si}$. We expect that it is related to chemical inhomogeneity, such as grain boundary segregation. Uesugi et al. also reported that the segregation tendency is likely to be inverse to that of the misfit strain $[16,17]$. In order to clarify experimentally, we investigated the distribution of minor solution is investigated by a newly developed EDS system.

\subsection{Chemical analysis of Si by microcalorimeter EDS with SEM}

Figure 3 shows a backscattered electron image of the Al$0.1 \mathrm{at} \% \mathrm{Si}$ alloy including the grain boundary. The grain boundary is geometrically characterized by OIM based on the EBSD and that is distinguished as the random boundary. Generally, at the random boundary, much more solutions tend to be segregated at the grain

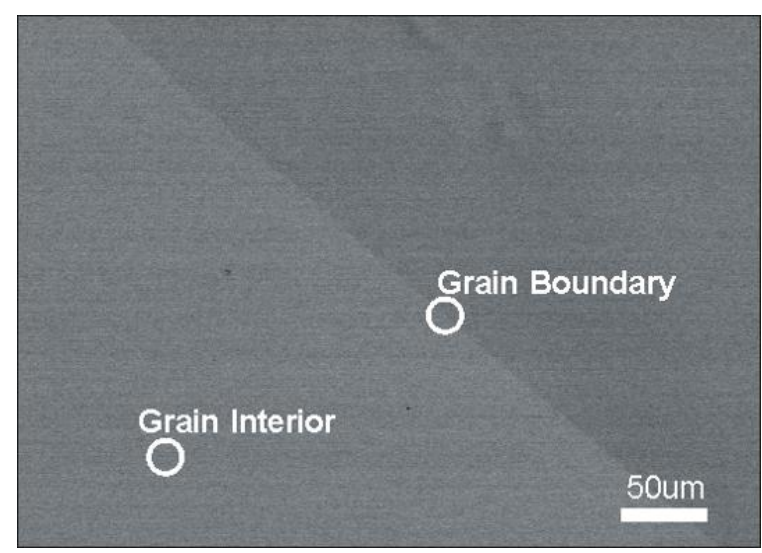

Figure 3 SEM image showing the grain boudanry in Al-0.04 at \% $\mathrm{Si}$ alloy. The geometrical relation of the both grains is the random boundary. The EDS analyses have conducted both of the grain boundary and grain interior indicated by white circle in the figure.

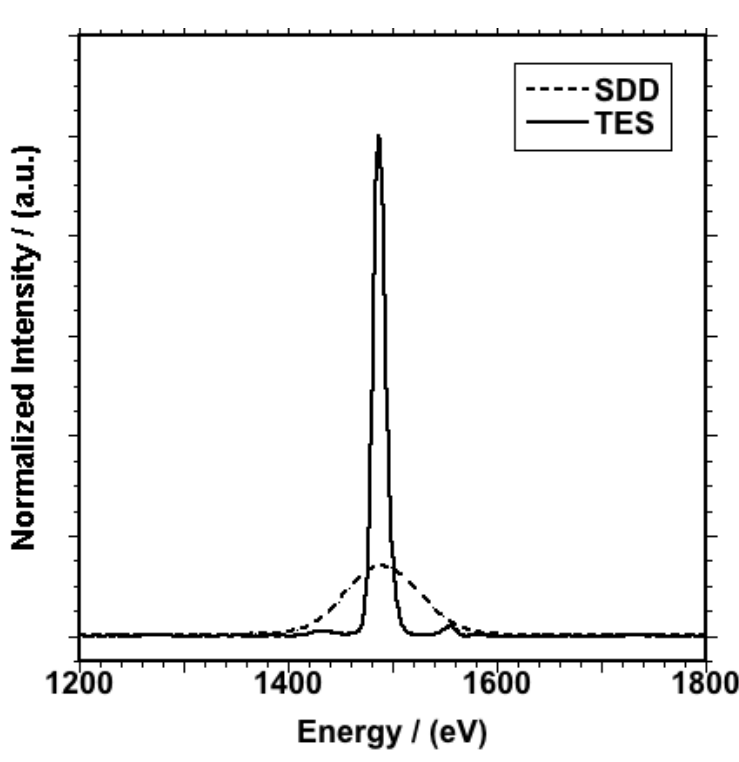

Figure 4 EDS profiles of Al-K $\mathrm{K}_{\alpha}$ taken from the grain interior in Al$0.04 \mathrm{at} \% \mathrm{Si}$ alloy by newly developed microcalorimeter type EDS (solid line) and the conventional SDD-EDS system (dotted line), respectively. Both profiles are normalized by the background. The profile taken by the microcalorimeter type EDS is much sharp than that by SDD-EDS, because of the high energy resolution of microcalorimeter type EDS [6]. Also, the small Al-K $\beta$ peak can be seen in the profile of microcalorimeter type EDS.

boundary compared with the low angle and coincidence boundary as low $\Sigma$ boundary ( $\Sigma$ value of less than 29 ). In order to clarify the grain boundary segregation of $\mathrm{Si}$ in the alloy, we analyzed it by the microcalorimeter type EDS analysis developed by Tanaka et al. [7]. In the same region, we also simultaneously analyzed by the conventional SDD-EDS system. Figure 4 shows the EDS spectra taken from the grain interior by TES and SDDEDS system, respectively. Both spectra are normalized by their background. The Al-K $\mathrm{K}_{\alpha}$ peak taken by the TESEDS is sharper than that by the conventional SDD-EDS. Both full width of half maximum (FWHM) were $130 \mathrm{eV}$ in SDD-EDS and $15 \mathrm{eV}$ in TES-EDS, respectively. Besides, the small peaks are also seen at both sides of the Al-K $\mathrm{K}_{\alpha}$ peak in the spectrum taken by TES-EDS. The small peaks detected at the higher energy side of Al$\mathrm{K}_{\alpha}$ is recognized as the $\mathrm{Al}-\mathrm{K}_{\beta}$ peak. The $\mathrm{Al}-\mathrm{K}_{\beta}$ peak is usually not seen in case of the SDD-EDS measurement because of its low energy resolution and $\mathrm{P} / \mathrm{B}$. The EDS spectrum becomes much broad and the $\mathrm{Al}-\mathrm{K}_{\beta}$ peak is masked by the main Al- $\mathrm{K}_{\alpha}$ peak as shown in the dotted line in figure 4. Figure 5 (a) and (b) are EDS spectra taken from the grain boundary and grain interior by SDD-EDS (a) and TES-EDS (b), respectively. The solid and dotted lines correspond to the spectrum taken from the grain boundary and grain interior, respectively in both figs.5 (a) and (b). All EDS spectra are only normalized with the main peak height of $\mathrm{Al}-\mathrm{K}_{\alpha}$ in each SDD and TES-EDS, respectively. In fig. 5 (a), the Si peak is hardly seen in EDS spectrum taken in both of the grain interior and the grain boundary because of the tailed Al- $\mathrm{K}_{\alpha}$ peak. On the other hand, many peaks can be seen in the spectra taken by the TES-EDS system as shown in fig.5 (b). In those spectra, not only Al-K $\mathrm{K}_{\alpha}$ and 
(a)

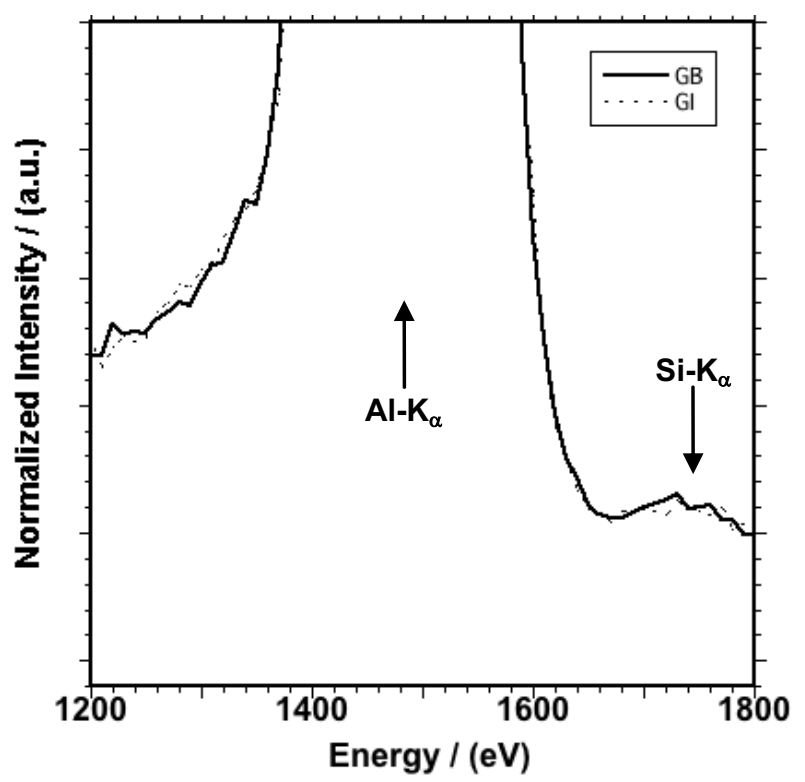

(b)

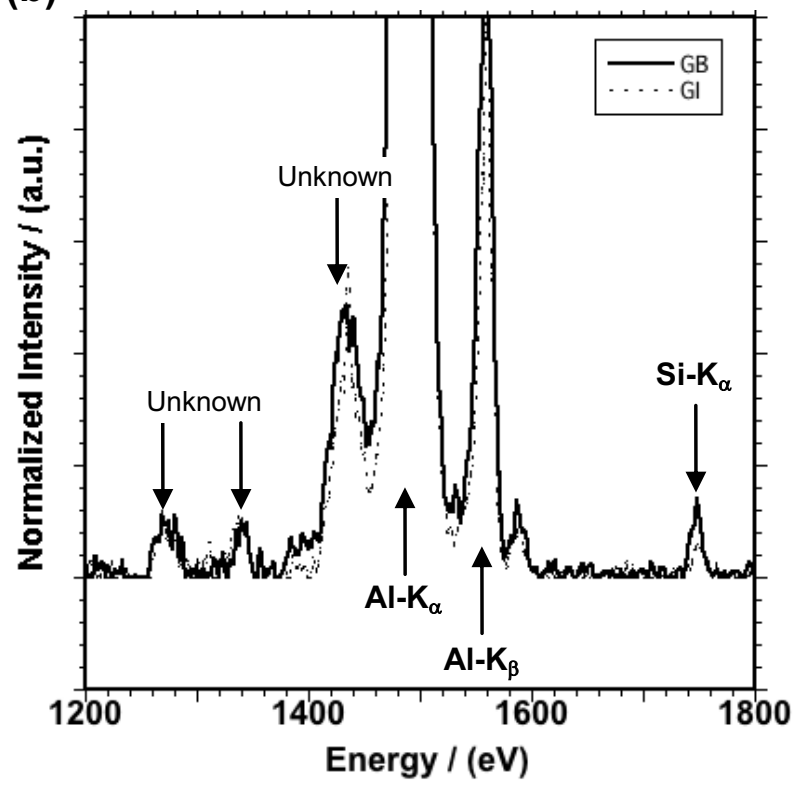

Figure 5 EDS spectrum taken by the conventional SDD-EDS (a) and newly developed microcalorimeter type EDS (b) system, respectively. All spectrum are only normalized by the main paek height of Al- $\mathrm{K}_{\alpha}$. In (a), main Al- $\mathrm{K}_{\alpha}$ and $\mathrm{Si}-\mathrm{K}_{\alpha}$ at $1740 \mathrm{eV}$ can be detected, but the peak of the $\mathrm{Si}-\mathrm{K}_{\alpha}$ is broad and small. Therefore, the EDS spectra taken at the grain boundary (solid line) and the grain interior (dotted line) are overlapped each other. On the other hand, the EDS spectra of the grain boundary and grain interior taken by microcalorimeter type EDS system in (b), shape Si-K $\mathrm{K}_{\alpha}$ peak can be detected. The height of both peaks is different each other and it suggests the grain boundary segregation.

Si- $\mathrm{K}_{\alpha}$ but also the other peak can be detected, because of the significant improvement of Peak / Background (P/B) ratio. The peak detected at slightly higher energy is identified as $\mathrm{Al}-\mathrm{K}_{\beta}$, however, unfortunately the other peaks cannot identified. In addition to the detection of Si-K $\mathrm{K}_{\alpha}$ peak in the TES-EDS measurement, the height of peaks taken at the grain boundary is higher than that of the grain interior. It suggests that the much $\mathrm{Si}$ is in the grain boundary, that is, grain boundary segregation is experimentally detected by the TES-EDS analysis, even if it is the less Si contents of 0.1 at $\%$. Concerning the grain boundary segregation, there are many reports about the impurities such as Sulphur and phosphorous in steel [18]. In the case of steel, the heat treatment at a relatively higher temperature and it is recognized as the equilibrium segregation. Moreover, surface analysis as auger spectroscopy can be easily conducted to the segregated grain boundaries in the steel than the Al. In the case of $\mathrm{Al}$, the quantitative analysis of grain boundary segregation was hard to be conducted, because of the low solubility and high ductility. The obtained result suggests that the quantitative analysis of TES-EDS enable us to analyze the local chemical composition even at low contents.

In our mechanical and analytical experiments, we examined the effect of $\mathrm{Fe}$ and $\mathrm{Si}$ on the local mechanical response in Al. Furthermore, we succeeded in the detection of the grain boundary segregation of minor $\mathrm{Si}$ in $\mathrm{Al}$ by the new EDS system. Consequently, we can consider that $\mathrm{Fe}$ act as a solute strengthening element in the Al matrix. On the other hand, since small misfit strain and the strong tendency of grain boundary segregation of $\mathrm{Si}$, it less influences their mechanical response in comparison $\mathrm{Fe}$. We found that the new techniques described above provide new findings for the relationship between the distribution of minor solutions and the strengthening. Unfortunately, $\mathrm{Fe}$ in $\mathrm{Al}$ was not detected simultaneously with Al by TES-EDS, through our experiments in the current situation. For it, the following reasons are expected. One is a detectability, and another is the energy range for the measurement. For the first one, although we have to clarify the lowest detection limit in this system, the modification of EDS system is also progressing. Concerning the energy range, the peak energies of $\mathrm{Al}-\mathrm{K}_{\alpha}$ of $1486 \mathrm{eV}$ and $\mathrm{Si}-\mathrm{K}_{\alpha}$ of $1740 \mathrm{eV}$ are close because the atomic number is next to each other, while $\mathrm{Fe}-\mathrm{K}_{\alpha}$ is $6398 \mathrm{eV}$, and it is far from that of $\mathrm{Al}-\mathrm{K}_{\alpha}$. If they are improved, even if $\mathrm{Fe}$ content is minimal, it would be detected in the Al matrix. Moreover, to clarify the inhomogeneous distribution, we also need to accumulate both mechanical and analytical data because of the orientation dependence of the mechanical property and the grain boundary character dependence of the segregation. Although we have a few issues, we will be at the stage to overcome the aforementioned problems, and the minor dopants being important in $\mathrm{Al}$ alloy can be detected.

\section{Conclusions}

We investigated the methodology to evaluate the distribution of the solute elements in $\mathrm{Al}$ from the standpoint of the mechanical response and chemical analysis. The following results are obtained.

1. In the nanoindentation, the pop-in event related to the dislocation nucleation and multiplication can be seen in $\mathrm{Al}$ alloys. The critical load, which is the load at the first pop-in event, increases with increasing of 
the $\mathrm{Fe}$ contents. However, less tendency of the increase of $\mathrm{Pc}$ is found in the Al-Si alloys. This is considered to be owing to their misfit strain and distribution of solute $\mathrm{Fe}$ and $\mathrm{Si}$, respectively.

2. Even for the small amount of 0.1 at $\% \mathrm{Si}$ in $\mathrm{Al}$, we succeeded in the apparent detection of Si peak by the newly developed microcalorimeter type EDS analysis. Besides, the peak height of $\mathrm{Si}-\mathrm{K}_{\alpha}$ at the grain boundary is higher than that at the grain interior, and it suggests that the grain boundary segregation occurs in Al-Si alloy. The first principle calculations for the tendency of the grain boundary segregation reported previously supports our results.

\section{Acknowledgments}

This work is partly supported by the grant-in-aid for scientific research (S) (16H06366). The microcalorimeter type EDS analysis are particularly supported by Advanced Characterization Platform of the Nanotechnology Platform Japan in Kyushu university sponsored by the Ministry of Education, Culture, Sports, Science and Technology (MEXT), Japan. We are also grateful to Dr. K. Tanaka for the fruitful discussion.

\section{References}

1. J. R. Davis ed. Aluminum and Aluminum Alloys (ASM International, Ohio, 1993)

2. ASTM E3061-17, Standard Test Method for Analysis of Aluminum and Aluminum Alloys by Inductively Coupled Plasma Atomic Emission Spectrometry (Performance Based Method), ASTM International, West Conshohocken, PA, 2017

3. ASTM E716-16, Standard Practices for Sampling and Sample Preparation of Aluminum and Aluminum Alloys for Determination of Chemical Composition by Spark Atomic Emission Spectrometry, ASTM International, West Conshohocken, PA, 2016

4. R. B. Schwarz, L. L. Funk, Acta Metall. 31, 299 (1983)

5. P. L. Rossiter, The electrical resistivity iof metals and alloys (Cambridge University Press, Cambridge, 1991)

6. D. Raabe, M. Herbig, S. Sandlöbes, Y. Li, D. Tytko, M. Kuzmina, D. Ponge, P. -P. Choi, Corr. Opin. Solid St. Mater. Sci. 18, 253 (2014)

7. K.Tanaka, A. Odawara, A. Nagata, M. Ikeda, Y. Baba and S. Nakayama, Surf. Interface Anal. 38, 1646 (2006)

8. P. M. Anderson, J. P. Hirth, J. Lothe, Theory of Dislocations (Cambridge University Press, Cambridge, 2017)

9. C. A. Schuh, Mater. Today. 9, 32 (2006)

10. C. A. Schuh, A. C. Lund, J. Mater. Res. 19, 2152 (2004)
11. L. Zhang, T. Ohmura, Phys. Rev. Lett. 112, 145504 (2014)

12. K.Sekido, T. Ohmura, L. Zhang, T. Hara, K. Tsuzaki, Mater. Sci. Eng. A. 530396 (2011)

13. H. Somekawa and C. Schuh, Acta Mater. 59, 7554 (2011)

14. T. Uesugi and K. Higashi, J. Jap. Inst. Light Metal, 54, 82 (2004) (In Japanese)

15. T. Uesugi, K. Higashi, Mater. Sci. Forum. 561-565, 977 (2007)

16. T. Uesugi, Y. Inoue, Y. Takigawa, K. Higashi, Mater. Sci. Forum. 551-552, 331 (2007)

17. Y. Inoue, T. Uesugi, Y. Takigawa, K. Higashi, Mater. Sci. Forum. 561-565, 1837 (2007)

18. P. Lajček, Grain boundary segregation in metals (Springer-Verlag, Berlin, 2010) 